\title{
AN INTERVENTION STUDY ON BEHAVIORAL \\ COMMITMENT BASED SAFETY IN SOME PETROLEUM \\ COMPANIES IN ALEXANDRIA
}

\author{
By \\ Hosny $\mathrm{G}^{1}$, Omran $\mathrm{I}^{1}$ and Foda $\mathrm{N}^{2}$ \\ ${ }^{1}$ Department of Environmental Studies, Division of Environmental Health, Institute of Graduate Studies and \\ Research, ${ }^{2}$ Department of Community Medicine, Faculty of Medicine, University of Alexandria, Egypt .
}

\begin{abstract}
Introduction: Safety problems are basically related to unsafe or careless employees. Many safety problems can be resolved, if behaviors are closely monitored and corrected. Studies found that the causes of accidents at workplace are due to workers' negligence, failure to comply with work procedures, and poor safety attitude. Aim of work: To determine the current status of workers' commitment for HSE (Health, Safety, and Environmental), management systems in some petroleum companies and provide evidence about the factors that should be encouraged to reduce risks and improve commitment in workers' behavior in these organizations. Materials and Methods: It comprised two parts; part I which was an inspection-based study for measuring the percentage of applying the occupational management systems according to OHSAS 18001/2007 in three petroleum companies using Accident Compensation Cooperation (ACC's) workplace safety management audit checklist (2017), and selection of the lowest committed company to apply the second stage, and part II which was intervention study by performing training sessions concentrating on behavioral based safety (BBS) to measure the relation of safety behavior with safety knowledge. Results: From the results of ACC's checklist, the company that had the lowest achievement percentage was Company A which had 75\% compliance with the OHSAS18001/2007. It was revealed that safety culture does not have a significant direct effect on personnel behavior before training $(\beta=0.112, \mathrm{p}=0.234)$ which was reversed after training $(\beta=-0.112, \mathrm{p}=0.000)$. Conclusion: The present study approved the significant influence of safety culture in ameliorating personnel safety behaviors in petroleum sites emphasizing the obligation
\end{abstract}


of organizations for behavioral changes to decrease unsafe conducts and improve safety processes and daily application routine.

Keywords: Behavioral Based Safety (BBS), Accident Compensation Cooperation (ACC's), OHSAS 18001/2007, and Petroleum safety.

\section{Introduction}

The Behavior Based Safety (BBS), Approach and Safety Improvement (ASI) revealed that the behavior based process was developed in 1998 and was introduced as a part of a broader accident prevention program. It was initially focused on "conventional" safety. Behavioral safety can improve safety behavior and reduce injuries (Dejoy, 2005).

In application BBS is a "bottom-up" approach where the primary attention is directed at specific safety related behaviors that are typically performed by frontline employees. Changes in the frontline safety behaviors will improve safety performance and over time will become a culture within the organization. The mode of safety intervention is effective significantly improving employee safety performance. The implementation of BBS showed a reduction of injuries rate, thus improving the performance (Abdul Rahim et al., 2008).
Behavior-based

approaches

is intended to safety focus on systematically studying the effects of various interventions on target behaviors related to the applicable certified safety management systems. This can be achieved firstly by defining the target behavior in a direct observable and recordable way, and secondly by observing and recording it in its natural setting. When a stable baseline measure of the frequency, rate, or duration of behavior is obtained, an intervention is implemented to change the behavior in beneficial directions. This intervention might involve removing environmental barriers, modifying a workstation, or adding antecedents or consequences to the situation to alter response probability. The frequency, duration, or rate of the target behavior is recorded during and after the intervention and compared to baseline measures of behavior to determine the impact of intervention (Cooper, 2009).

Further, studies suggested that the typical implementation of behavior- 
based safety program should involve well-defined steps (Cox et al., 2004).

\section{Aim of work}

To determine the current status of workers' commitment for HSE (Health, Safety, and Environmental), management systems in some petroleum companies and provide evidence about the factors that should be encouraged to reduce risks and improve commitment in workers' behavior in these organizations.

\section{Materials and Methods}

- Study design: It comprised two parts; part I which was an inspectionbased study for measuring the percentage of applying the occupational management systems according to OHSAS 18001/2007 in three petroleum companies using Accident Compensation Cooperation's (ACC's) workplace safety management audit checklist (2017), and part II which was intervention study related to BBS that was applied on one of the selected companies to measure the relation between safety behavior and safety knowledge before and after training.
- Place and duration of study: The study was conducted on workers of three petroleum companies at Alexandria from January 2016 to May 2017.

\section{- Study sample:}

Part I: The inspection-based study was conducted on three petroleum companies who accepted to join the study (convenient sample). The criteria for sample selection were: the company should be certified as an integrated management system (OHSAS 18001, ISO 14001 and ISO 9001) and achieve the lowest percentage of compliance with OHSAS 18001/2007 requirements.

Part II: The intervention study that was applied on one of the selected companies to measure the relation between safety behavior and safety knowledge. Among 960 workers (representing the whole working population), the total number of workers who agreed to participate in this study was one hundred (No. $=100$ ). The intervention study comprised five training package on the following: 
1. OHSAS 18001/2007 "comply and audit of health and safety management system" (No. of training candidates $=100$ )

2. NEBOSH, National Examination Board on Occupational Safety and Health, in oil and gas (No. of training candidates $=25$ ).

3. NFPA, National Fire Protection Association, 1035, standard for professional qualifications for public fire and life safety educator (No. of training candidates $=25$ ).

4. NFPA learn not to burn, a safe escape house (No. no. of training candidates $=50$ )

5. OSHA "introduction to occupational safety and health administration" (No. of training candidates $=50$ ).

\section{-Study methods}

A pre designed questionnaire was used; the interview was carried out in the head of departments' offices at the company during the work day without interruption of the working schedule. Each questionnaire was completed within the range of 15 to
20 minutes with the participation of an average of 10 subjects/ setting. Accident Compensation Cooperation (ACC's) workplace safety management audit checklist (2017) to measure the company's practices in health and safety management system was used in three petroleum companies. British Standard Institute (BSI) OHSAS 18001/2007 checklist (2017) and DOW Chemical Company Safety Behavior checklist (2013) for safety behavior were used in the intervention study before and after training. The scale respondents to take a stand as to what degree they comply with each item, and are scored as follows: comply=Yes; not fully comply=No; not applicable or no prove $=\mathrm{N} / \mathrm{A}$.

The BSI audit checklist has been adapted and modified to 6 clauses according to OHSAS 18001/2007 elements to evaluate, assess the health and safety management systems. It has proven reliable and valid. It contains positively and negatively formulated items using a seven-point complying scale. The scale respondents to take a stand as to what degree they comply with each item, and are scored as follows: 
- Fully documented and fully applied.

- Partially documented and fully applied.

- Un-documented and fully applied.

- Fully documented and partially applied.

- Partially documented and partially applied.

- Not documented and partially applied.

- Not documented and not applied, or I do not know.

The safety action checklist has been adapted and modified to 32 questions according to DOW chemical company's safety behavior self-checklist to evaluate, assess the awareness and understanding of safety techniques.

The safety behavior questionsnine element sheet of solo audit survey assesses the following: Employer commitment to safety management practices; Planning review and evaluation; Hazard identification, assessment and management; Information, training and supervision; Incident and injury reporting, recording and investigation; Employee = high knowledge. participation in health and safety management; Emergency planning and readiness; Protection of employees from on-site work undertaken by contractors and sub-contractors; and Workplace observation confirmation of safe systems in action.

\section{BSI questionnaire assesses} the following: Commitment and policy; Planning; Implementation and operation; Checking; audit; and Management review.

DOW questionnaire assesses the following: Personal protective equipment; Protective defenses; Positions/ actions of people; Tools (file, grinder, stringer, wrench, etc.); Equipments (cranes, bobcat, etc.); Housekeeping; Procedures; and Special high risk jobs.

The score in Modified BSI ranges from $0-6$, where 0 is the lowest score and 6 is the highest score and belong to the following criteria: Score zero $=$ no knowledge; Score one and two = little knowledge; Score three and four medium knowledge; Score five and six 
The score in modified Dow ranges from $0-3$, where 0 is the lowest score and 3 is the highest score and belong to the following criteria: Score zero and one $=$ low behavior; Score two $=$ medium behavior; and Score three $=$ high behavior.

\section{Consent}

Verbal consent was obtained from study subjects before the start of work with assurance of confidentiality and anonymity of the data.

\section{Ethical approval}

Approvals of the administrative authority of the Companies were obtained. Also, the study protocol was approved by Ethical Research Committee of Institute of Graduate
Studies and Research, Alexandria University.

\section{Data management}

The data collected through the Modified BSI with DOW items were revised, coded, analyzed and fed to statistical software SPSS Statistics (IBM-SPSS Statistics, 2010) version 20. The given graphs were constructed using Microsoft Office Excel (2007 and 2016). Binary logistic regression analysis was used for prediction of independent variables related to BBS. Significant predictors in the univariate analysis were entered into the regression model. Odds ratios and their 95\% confidence interval were calculated. "p value $\leq 0.05$ " was considered to be statistically significant and $\leq 0.01$ was considered highly significant. 


\section{Results}

\section{Part I: Results of the inspection-based study.}
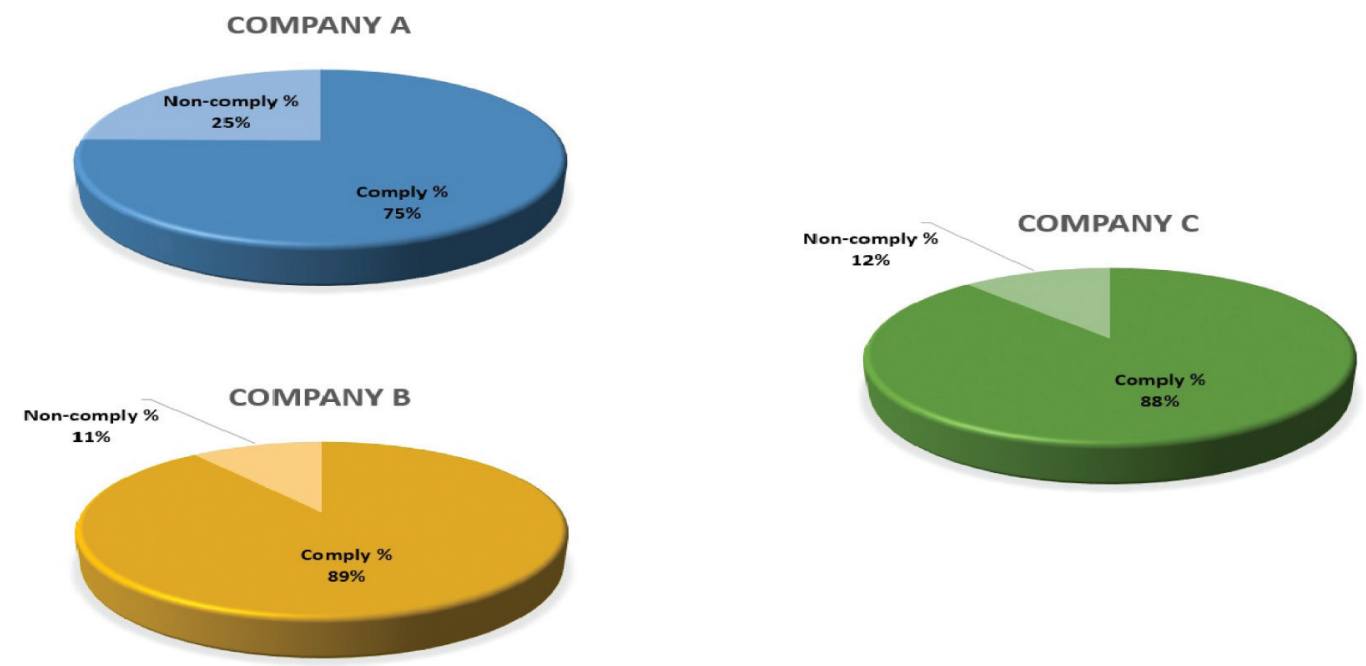

Figure 1: The total percentage of companies' health and safety management system compliance with OHSAS17001/2007 audit survey.

The ACC's workplace safety management audit checklist deduced the percentage of companies' health and safety management system achievement with the nine elements of solo audit survey, as illustrated in Figure 1.

From the result of ACC's checklist, the company that had the lowest achievement percentage was Company A which had $75 \%$ compliance with the OHSAS18001/2007.

Thus Company A was chosen for the intervention study, using the BSI and DOW questionnaires to measure the worker commitments for safety and understanding the safety and health management systems. 


\section{Part II: Results of the Modified BSI and DOW Questionnaires}

Table 1: Regression model for behavior with intervention\# before and after training.

\begin{tabular}{|c|c|c|c|c|c|c|}
\hline & \multirow{2}{*}{ Model } & \multicolumn{2}{|c|}{$\begin{array}{l}\text { Unstandardized } \\
\text { Coefficients }\end{array}$} & \multirow{2}{*}{$\begin{array}{c}\text { Standardized } \\
\text { Coefficients Beta }\end{array}$} & \multirow{2}{*}{$\mathbf{t}$} & \multirow{2}{*}{ Sig. } \\
\hline & & B & Std. Error & & & \\
\hline \multirow{2}{*}{1} & (Constant) & 16.143 & 18.526 & & 0.871 & 0.386 \\
\hline & Behavior B. & 0.254 & 0.291 & 0.088 & 0.874 & 0.384 \\
\hline \multirow{2}{*}{2} & (Constant) & 97.379 & 8.660 & & 11.245 & $.000 *$ \\
\hline & Behavior A. & -0.118 & 0.098 & -0.112 & -1.197 & 0.234 \\
\hline
\end{tabular}

1: Coefficients before training,

Behavior B. stands for behavior before training,

2: Coefficients after training,

Behavior A. stands for behavior after training,

\#Dependent Variable: Knowledge before or after training,

*Statistically significant.

Table 1 showed the regression model for safety behavior before and after training. As illustrated, behavior was significantly changed after training emphasizing the role of training in improving safety behavior. 


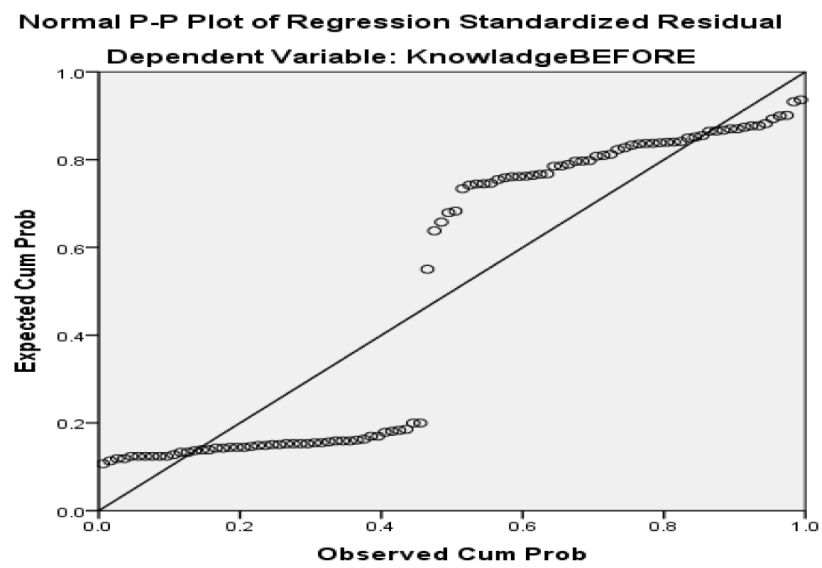

Figure 2: Regression analysis for the behavior before training in relation to safety knowledge.

Figure 2 showed a big gap between observed and expected cumulative probability, illustrating poor safety behavior in the studied company.

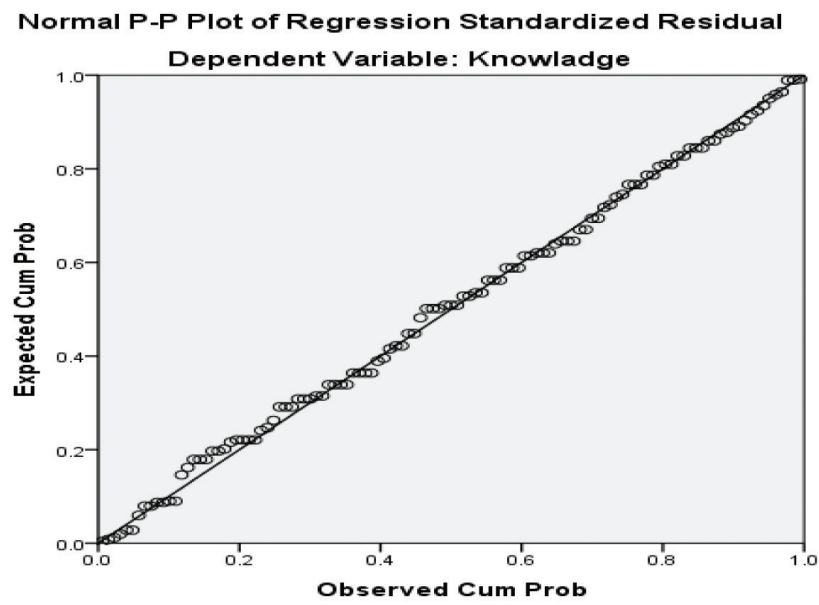

Figure 3: Regression analysis for behavior after training in relation to safety knowledge.

Figure 3 showed a linear relation between observed and expected cumulative probability, illustrating the improvement in safety knowledge and behavior with training among the studied company. 


\section{Discussion}

Safety knowledge, as a core interpreter of personnel safety motivation to safety behavior, was investigated. Safety culture as a second order latent factor was conceptualized by five main first order factors including management commitment toward safety, employee attitudes toward safety, co-workers' safety support, behavioral workplace pressure and behavioral sites' safety management systems. The current study showed that safety culture has a significant positive influence on personnel motivation to safe behavior (Table 1; $\beta=0.088, p=0.384$ before training and $\beta=-0.112, p=0.000$ after training).

Furthermore, the finding highlights the significant contribution of safety management systems and management commitment to improve personnel safety motivation to petroleum safety by involving them in safety processes, accommodating their safety concerns, assigning clear safety accountability to enable personnel to make crucial decisions about safety problems, and more essentially, to empower the personnel to be more committed to adhere, as well as to improve safety daily rules and procedures. Mohamed (2002) conducted a safety climate investigation study on workers' behavior in 10 different construction companies in Australia. He used different aspects of safety climate including management commitment, communication, workers participation, attitude, capability and skills, management positive monitoring, safety rules and procedure and supportive environment. The results of the study stated that safety climate has a positive impact on a supportive environment and positive monitoring, which are directly related to safety motivation. Many studies evaluated safety climate dimensions and they concluded that employee safety empowerment and motivation are greatly affected by safety culture (Mohamed, 2002; Mohamed, 2003; Mohamed et al., 2009; Geller, 1994; Wiegmann and Shappell, 2001; Wiegmann et al., 2004; Choudhry and Fang, 2008).

Safety culture is positively supported by management commitment, management support, workers motivation through awards to good safety culture (Vecchio-Sadus and 
Griffiths, 2004; Choudhry and Fang, 2008). Based on the questionnaire approach of their study, they stated that behavioral improvement and good safety behavior reassurance are the main blocks that a good safety program consists of, which is similar to the after training results in the current study (Figure 3). Also, Ismail et al. (2012) stressed in their study that safety culture has an influence on management support and workers motivation because they are considered as safety climate elements. This agreed with the findings of this research work as regard the influence of safety culture on personnel safety motivation to safe behavior (the intervention section of the study).

The final results in this work are related to the direct effect of safety culture on personnel error behaviors. Safety culture did not have a significant direct effect on personnel behavior before training (Table 1; $\beta=0.112$, $\mathrm{p}=0.234)$ which was reversed after training (Table 1; $\beta=-0.112, \mathrm{p}=0.000$ ). Personnel awareness about safety culture in petroleum is not sufficient to influence error behaviors. Fogarty
(2004) and Fogarty and Shaw (2010) investigated safety climate effect on maintenance personnel error behaviors. They concluded that error behaviors of maintenance personnel could not be interpreted only through safety climate directly. This supported our study results in which safety culture has no direct effect on personnel error behavior.

\section{-Study Implication:}

The present study has several implications for safety culture research in behavioral field and also for Petroleum Company's field. First of all, the study indicated that safety knowledge has a significant effect on personnel safety motivation to safe behavior. This outcome implies the substantial need to assess and enhance safety knowledge in behavioral sector. Petroleum companies' top management personnel should concentrate on appraising and improving the current safety culture in the behavioral sites, which, in accordance, will improve personnel safety motivation to behavioral safety. In order to improve the latter, Egyptian petroleum government behavioral officials should have a high management commitment 
to safety, enhance employee attitudes through safety awareness and should get workers involved in decisions regarding safety.

Second, the present research confirmed the significant influence of safety culture role in forming personnel safety behaviors in petroleum sites. Safety culture did have a direct and significant effect on behavioral personnel attitudes toward risks and an indirect impact on behavioral personnel error behaviors through safety motivation. These outcomes emphasize the obligation of Egyptian petroleum governmental behavioral management to decrease unsafe conducts and improve safety processes and daily application routine. These results highlight the urgent need to examine safety management systems, accidents and near miss cases to find out the organizational characteristics that took part directly or indirectly in influencing unsafe performance. Egyptian petroleum government behavioral management should not directly make the decision to blame personnel for unsafe acts, but instead they should explore the elements behind their behavior to make an error or risk behavior.

\section{Conclusion and Recommendations}

Organizational culture elements influenced personnel behaviors when performing a required task in the work environment. A focus on understanding and applying safety culture concept in the behavioral field is essential to assure the safety of behavioral personnel in this high-risk work.

As a future research prospect, researchers may explore the differences among subcultures formed under the general safety culture within the same context of high risk organization field including variety of industries, manufacturing and mining. This examination of the variances among each industrial division, along with differences between each country's safety cultures, will highlight the positive and negative characteristics of organizational safety culture in such a way that elaborates and develops the current knowledge.

\section{- Limitations of the study:}

This research has the limitations that are inherent in studies using perceptions 
and self-reported response data. It would have been much better if more organizations are involved in the study. Since this study was a case study that was carried out during a short period of time, there is a scope for a longitudinal study to validate the findings.

\section{Conflict of interest}

\section{None}

\section{References}

1. Abdul Rahim AH, Muhd Zaimi AM and Bachan S (2008): Causes of Accidents at Construction Sites. Malaysian Journal of Civil Engineering; 20(2): 242-259.

2. Accident Compensation Cooperation (ACC's) (2017): ACC's workplace safety checklist; available at: www.acc.co.nz/approvedauditors. or http://hsu.caa.govt.nz/assets/Uploads/ Forms-and-guides/ACC442-Measuring-yourcapabilities-in-Workplace-Safety-Management. pdf

3. Choudhry RM and Fang D (2008): Why operatives engage in unsafe work behavior: Investigating factors on construction sites. Safety Science; 46(4): 566-584.

4. Cooper MD (2009): Behavioral Safety: A review of process design factors. Professional Safety; 54 (2): 36-45.

5. Cox S, Jones B and Rycraft H (2004): Behavioral Approaches to Safety Management Within UK Reactor Plants. Safety Science; 42(9): 825-839.

6. Dejoy DM (2005): Behaviour Change versus Culture Change: Divergent Approaches to Managing Workplace Safety. Safety Science; 43(2): 105-129.

7. Fogarty GJ (2004): The Role of Organizational and Individual Variables in Aircraft Maintenance Performance. International Journal of Applied Aviation Studies; 4(1): 73-90.
8. Fogarty GJ and Shaw A (2010): Safety climate and the theory of planned behavior: Towards the prediction of unsafe behavior. Accident Analysis \& Prevention; 42(5): 1455-1459.

9. Geller ES (1994): Ten principles for achieving a total safety culture (TSC). Professional Safety; 39(9): 18-24.

10. Ismail F, Ahmad N, Janipha NAI and Ismail R (2012): Assessing the behavioral factors' of safety culture for the Malaysian construction companies. Procedia-Social and Behavioral Sciences; 36: 573-582.

11. Mohamed S (2002): Safety climate in construction site environments. Journal of Construction Engineering and Management; 128(5): 375-384.

12. Mohamed S (2003): Scorecard approach to benchmarking organizational safety culture in construction. Journal of Construction Engineering and Management; 129(1): 80-88.

13. Mohamed S, Ali TH and Tam W (2009): National culture and safe work behaviour of construction workers in Pakistan. Safety Science; 47(1): 29-35.

14. The BSI OHSAS 18001/2007 checklist, (2017). Available at: https://www.bsigroup.com/ LocalFiles/en-GB/bs-ohsas-18001/resources/ BSI-BSOHSAS18001-Assessment-ChecklistUK-EN.pdf

15. The Dow Chemical Company safety behavior checklist - Meet Behaviour Expectations Work Process, Behavior Based Performance Sub-Process. (2013). https://www.coaa. ab.ca/COAA-Library/SAF-BBS-CBP-01NOYR-v $1 \% 20$ Behaviour $\% 20$ Based $\% 20$ Safety $\% 20$ Best $\% 20$ Practice $\% 20$ with $\% 20$ supporting\%20docs.pdf

16. Vecchio-Sadus AM and Griffiths S (2004): Marketing strategies for enhancing safety culture. Safety Science; 42(7): 601-619.

17. Wiegmann DA and Shappell SA (2001): Human error perspectives in aviation. The International Journal of Aviation Psychology; 11(4): 341-357.

18. Wiegmann DA, Zhang H, Von Thaden TL, Sharma G and Gibbons AM (2004): Safety culture: An integrative review. The International Journal of Aviation Psychology; 14(2):117-134. 